\title{
ERRATUM
}

doi:10.1038/nature08545

\section{Remote triggering of fault-strength changes on the San Andreas fault at Parkfield}

Taka'aki Taira, Paul G. Silver, Fenglin Niu \& Robert M. Nadeau

Nature 461, 636-639 (2009)

In Figure 2a of this Letter, in the key, the green line was inadvertently labelled 'SMN' instead of 'CCRB'. Also, in Figure 2c, the $y$-axis label should be 'Recurrence interval (d)' and not 'Recurrence index (d)'. The correct figure is shown below.

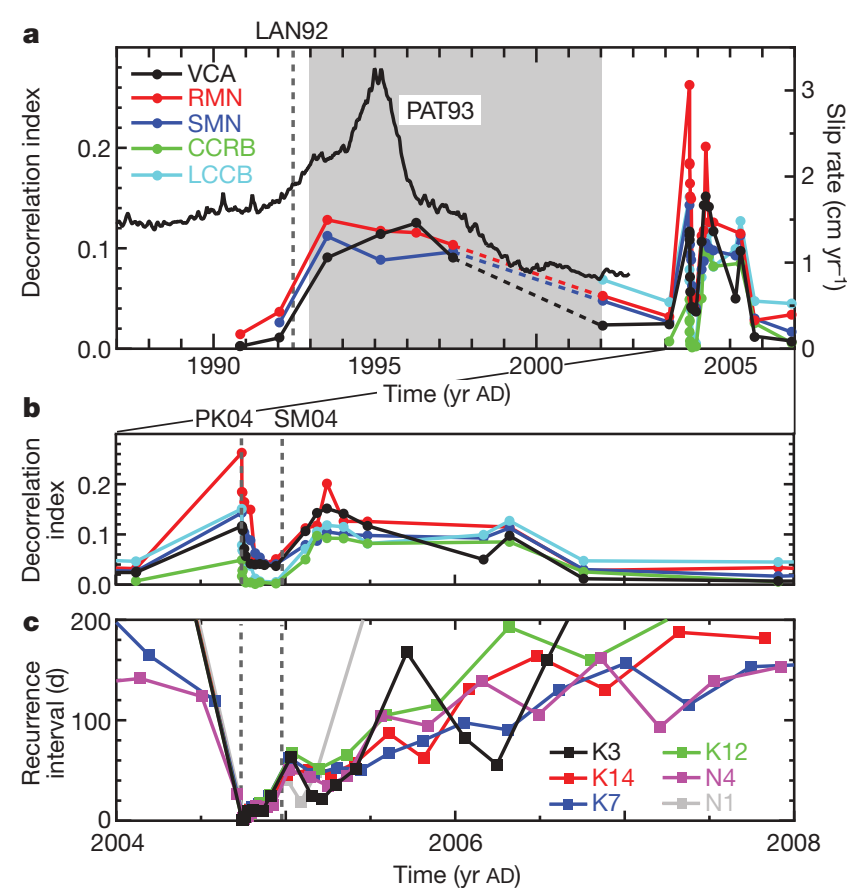

